\title{
The Management of a Locomotive Repair SHOP.
}

Paper read before the Institution by Colonel O'Brien, D.S.O., Member, Horwich, on 8th October, 1920, at Manchester.

\section{Paper No. 86.}

The Author, in presenting a Paper to this Institution on this important aspect of railway work, has not dealt in detail with actual shop methods or machining operations in spite of the fact that such methods offer a larger field for discussion than is presented by the consideration of general principles.

The work of repairing locomotives is a highly specialised branch of mechanical engineering, though in general it does not demand quite the same accuracy of work or refinements of method demanded in such branches of engineering as the machine tool or motor car manufacturing trades. Each railway company's method is founded on the practical experience of many years, and while these methods do not vary much in general principles, there is much variation in detail on the design of the locomotives and on the shop equipment depending on the method of organisation adopted. The following notes first describe the general principles applicable to the problem of locomotive repairs, and these notes have been amplified by a more detailed description of the methods adopted by the L. and Y. Rly. Co. at Horwich.

It should be noted at the outset that the main objective of the management of a railway locomotive workshop is essentially different from that of a commercial manufacturing works; the engineering management of a commercial engineering works desire to see a constant expansion of their shops, while in the case of the railway management their desire should be to see a constant shrinkage of the shops brought about by

(I) Improved methods of manufacture.

(2) Improved organisation.

(3) Rectification of errors in design and material with the object of reducing renewals and repairs to a minimum. 
It is possible to effect this because the capital expansion of the locomotive stock is very slow on English railways, and therelore the capacity of the works should more than keep pace with the demands if the management is progressive, in spite of the increatsed weight and power of the more modern stock.

The number of locomotives on the L. and Y. Railway has only increased from $\mathrm{r}, 326$ to $\mathrm{r}, 645$ in the last 20 years. The ain of every railway management should therefore be to effect improvement in the cost of repairs at a greater rate than the capital expansion, so that far from requiring additional shop room, increased floor space will steadily become available in the existing shops, while the number of employees remains constant or even decreases.

While patient attention to methods of manufacture on existing machines will result in increased output, the best results will not be attained unless the most modern and most highly productive and specialised machinery is, on a commercial basis, applied to the work as rapidly as the machine tool manufacurers make it available.

A machinery renewal fund should exist in every works based on a ten years' life of the machinery in order to allow for both wear and tear and obsolescence. This may seem a short life, as many machines are in good condition after thirty years' work, but it must be remembered that though from time to time little advance may appear to be taking. place in tool steel and machine design, yet over the last fifty years progress has been rapid and continuous. The introduction of high speed steel between 1903 and I9Io put many machines simultaneously on the scrap heap; higher speed steels and compound cutting metals such as "Stellite" are in sight, and funds should be available in every works to cnable the fullest advantage to be taken of such improvements.

It must be understood that the Author does not advocate the wholesale purchase of new and more powerful machines purely on an arbitrary basis. 'There may be said to be one method of procedure sounder than any other which must be based on a knowledge of the existing annual output of each article dealt $w$ ith. These records are easily obtainable from the time sheets, and can be classified by clerical labour under technical supervision. This work is done partly by the checking staff and partly by clerks, the total clerical staff engaged on the work consisting of three clerks.

To illustrate this procedure more fully an example is 
LANCASHIRE \& YORKSHIRE RAILWAY CO., HORWICH.

MANAGER'S OFFICE.

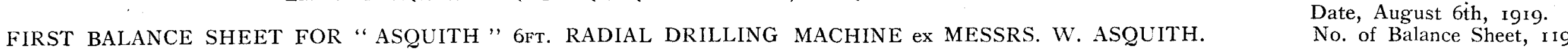

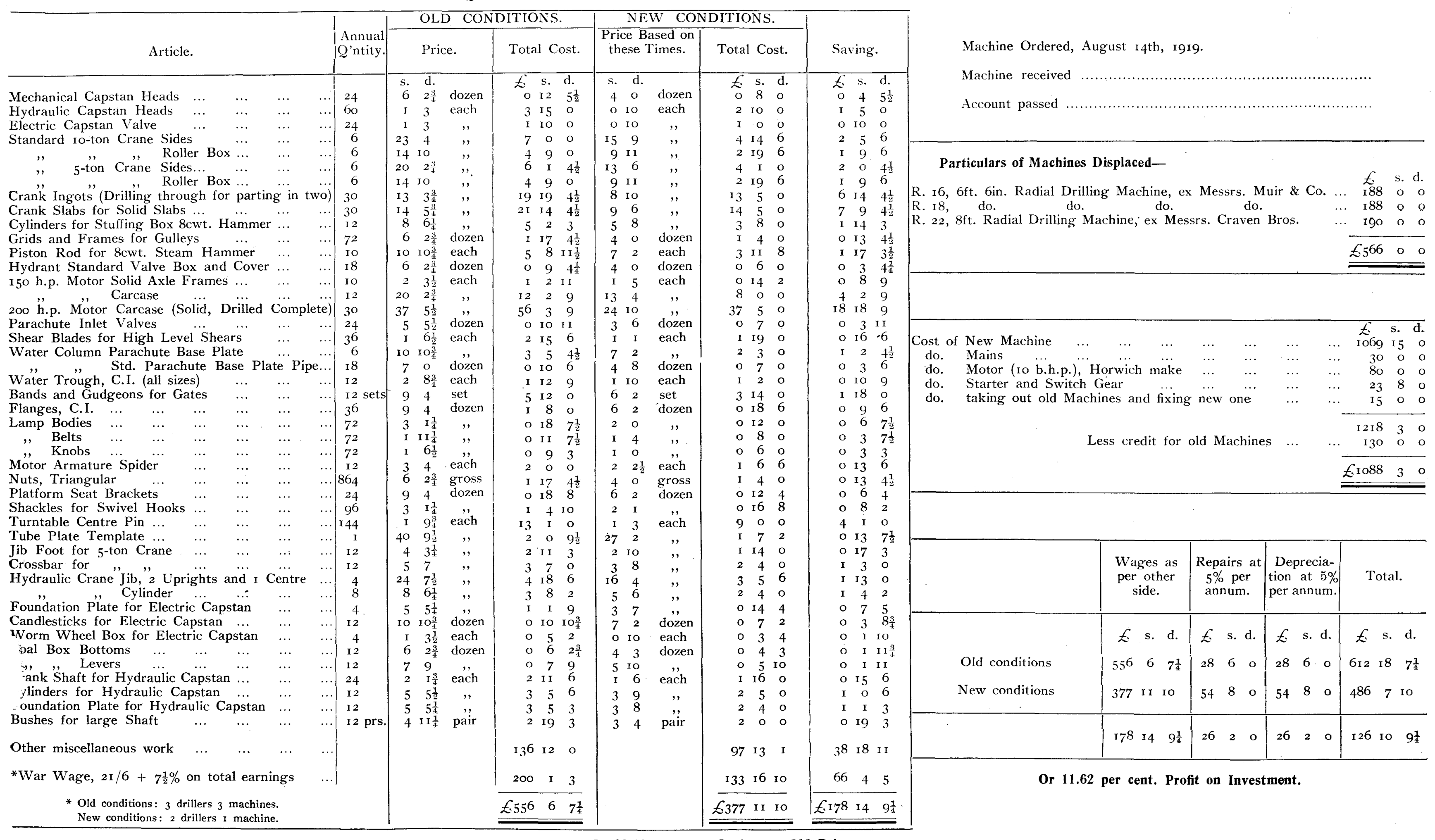

Or 32.12 per cent. Saving on Old Prices.

Fig. I. 

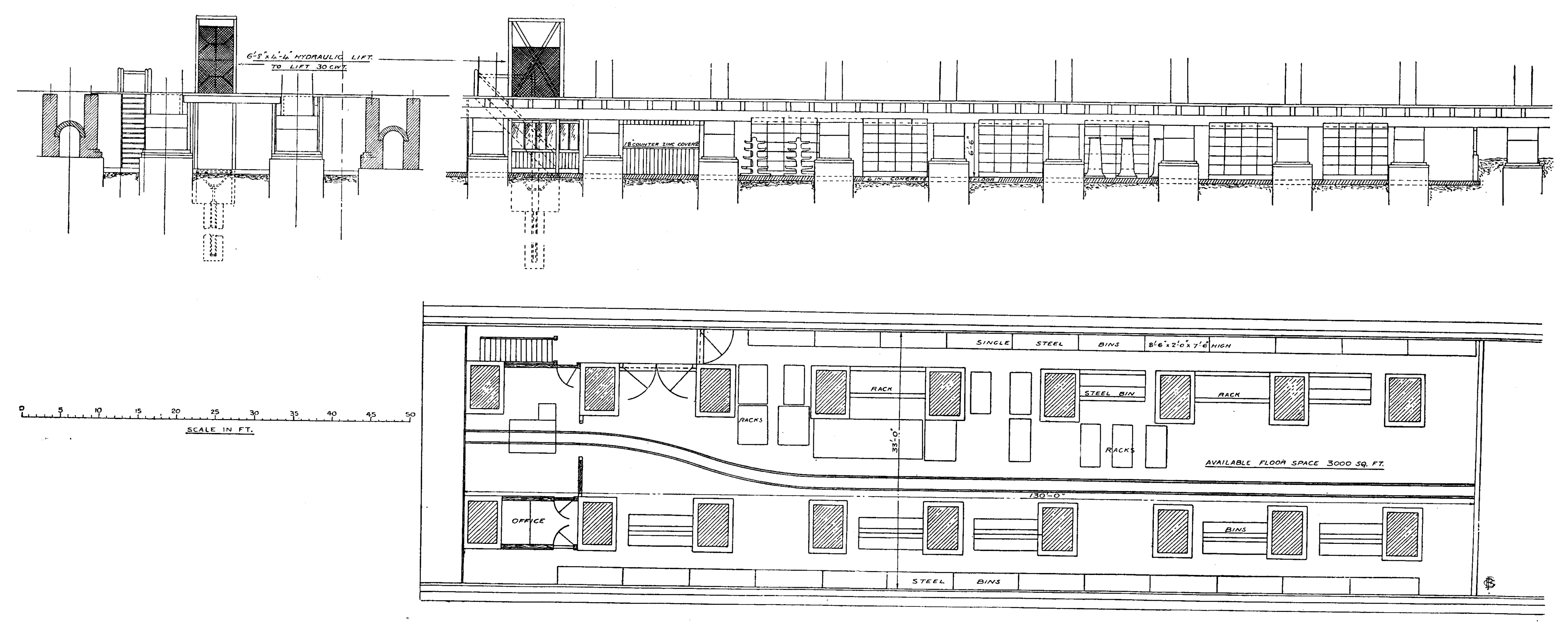

Fit: 2. Finishej Work Stores undir No. 5 Erecting Shop, Horwtoh. 
given in connection with drilling operations. These jobs carried out on three old machines have been tabulated with existing prices or costs; new piecework prices have been worked out for these articles by the rate fixer on the basis attainable with the new machine (in most cases it is good policy to send samples to the machine tool maker and obtain guaranteed times); a balance sheet is then prepared as illustrated in Fig. I, showing the return obtainable on the capital expenditure. After all necessary allowances have been made the return should be such as to enable the machine to make its own contribution to the renewal and obsolescence fund, or in other words, it is hardly justifiable to purchase a new machine unless a return of approximately 8 per cent. on the capital expenditure is obtainable. There is another broader and more approximate way of looking at the problem on the basis that where two new machines can be installed to do the work of three existing ones, the gain in floor space and the reduction in labour cost will justify a capital expenditure of $E_{2}, \infty 00$, to per cent. on this sum representing the cost of one machinist's wages per annum. When the purchase of a machine has been decided upon, a profit and loss ledger account is opened in the Works Manager's Department, which shows the work done by the machine and the economy effected over the piecework prices, which would have had to be paid had the old machine been retained. The exact return attained by the purchase of new machines over a prriod of years is therefore known. The above are both rough and ready methods, open to considerable criticism from an accountant's point of riew, but in practice they produce good results.

Modern high speed machines must be flled with work to their full capacity if an adequate return is to be obtained from them; this requirement involves either a large stock of locomotives very fully standardised or the manufacture of parts for stock, or a combination of both these requirements. Intelligent manufacture for stock involves a knowledge of the maximum and minimum weekly or monthly demands for each article, which in turn demands the issue of all machined or manufactured parts, whether new or repaired through the books of a finished work store. Such a store has long been under consideration at Horwich, and was finally, in order to avoid unnecessary building, installed under the erecting shop floor, the general arrangement of which is shown in Fig. 2 .

Other salient points requiring the closest possible attention are :- 
(1) The reduction of unnecessary work to a minimum; this can be effected by-

(a) Inspection of all parts of the locomotive after stripping and cleaning for both flaws and wear; this procedure confines the functions of the machine shop to their legitimate sphere of effecting repairs on definite lines laid down by the Management.

(b) Elimination of all unnecessary machining operations; this can only be satisfactorily effected by the use of operation sheets, samples of which are shown in Figs. 3 and 4. Close scrutinising of machining operations by a competent staff of young foremen with modern ideas will often result in a surprisingly large elimination of unnecessary operations.

(c) Elimination of fitting operations by the use of limit gauges, jigs, machining particularly by grinding instead of scraping, filing, and chipping, e.g., no scraping should be done on any surface which can be reached by a grinding machine; every use of the chisel or file should be regarded as an adverse criticism of the quality of the machine work or the system of standardisation, or the design.

(2) The reduction of unnecessary transportation of material by-

(a) Such methods as the arrangement of all white metalling and coppersmiths' work in the closest vicinity to the erecting shop; suitable location of the cleaning boshes and labour-saving appliances in connection therewith.

(b) Locating benches in the vicinity of the machines principally dealing with the work of those benches or vice versa grouping machines specially dealing with the work of the bench in its vicinity, always provided, of course, that the machines can be fully occupied. The arrangement of the machine shop at Horwich is illustrated in the block plan, Fig. 5.

(c) By the retention in the erecting shop of all material proved by inspection not to require repairs.

(3) The closest economy in the use of material to be effected- 


\section{LANCASHIRE \& YORKSHIRE RAILWAY.}

\section{MASTER OPERATION CARD.}

MACHINE SHOP

SHOP
Horwich Wortis.

Drawing No 12380 wise The toead

Pattern No. 12755 .

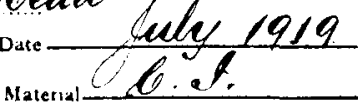

\begin{tabular}{|c|c|c|c|c|c|c|c|c|c|}
\hline $\begin{array}{l}\text { Opera- } \\
\text { tion No. }\end{array}$ & Description of Operation. & Limit Gauges. & $\begin{array}{l}\text { Tुg. } \\
\text { No }\end{array}$ & $\begin{array}{l}\text { Fix- } \\
\text { tures }\end{array}$ & $\begin{array}{c}\text { Machios } \\
N_{0}\end{array}$ & $\begin{array}{l}\text { Sec- } \\
\text { tion }\end{array}$ & $\frac{P_{\text {NII }}}{\mathrm{s.}}$ & $\begin{array}{l}\text { each } T_{11} \\
\text { d. H }\end{array}$ & $\begin{array}{l}\frac{1}{\text { ice Vothe }} \\
\mathrm{M}\end{array}$ \\
\hline $1^{s 5}$ & Surning y B̈orene & 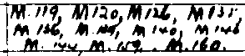 & & & 231 & 9 & 3 & 6 & 30 \\
\hline $2+d$ & Devachereq Thew way & $M 391$ & & & 324 & 5 & & 24 & $8 \frac{2}{2}$ \\
\hline $3^{\frac{n d}{6}}$ & Slot Qdvilling Yteryuar & M390 & $M$ & & 173 & 2 & ( & $4 \frac{1}{2}$ & 18 \\
\hline $4^{\frac{4}{*}}$ & Tittime no for Gilling & & & & BENO & 8 & . & $\cdot x$ & \\
\hline $5^{\infty 6}$ & Suelling Happing & $M_{1} 130, M_{113}, M_{12} q_{1}$ & $M I^{2}$ & & 33 & $\boldsymbol{r}$ & $y$ & 82 & 0 \\
\hline $6^{87}$ & Titteng Ball Telease babu bof & & & & Benel & 8 & &. & \\
\hline$\gamma^{\alpha x}$ & Sacing ede - do - & & & & 240 & 9 & & $y_{4}^{\frac{1}{4}}$ & 24 \\
\hline $8^{\alpha \gamma}$ & Hetting Mall Delease láles, & & & & & & & & \\
\hline & 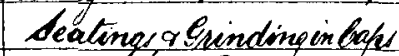 & & & & Bere & 8 & 5 & $9 \frac{3}{4}$ & 4 \\
\hline $9^{8}$ & Adjusting Ploings. & & & & 240 & 9 & 3 & & 11 \\
\hline & & & & & & & & & \\
\hline & & & & & क्tat & & 21 & $2 \frac{3}{4}$ & $540^{2}$ \\
\hline & & & & & & & & & \\
\hline & & & & & & & 1 & & \\
\hline
\end{tabular}

Fig. 3. 
(a) By specialised inspection for wear, relieving the fitter of the responsibility for deciding when a part is to be renewed.

(b) By a continuous watch for fresh points where wear can be reduced by the use of hardened and ground surfaces.

(c) By the extensive use of graduated sizes of pins and holes and by the use of renewable harden.ed and ground bushes wherever possible. See description in Appendix B.

(d) By the regular inspection of all scrapped material with the object of reconditioning or utilising for the manufacture of new articles of a smaller size. and directing scrap to the points where it could be best worked up. A scrap inspection shop should be a unit in every large locomotive repair works, serving the dual purpose of saving material and improving design.

(e) By the close analysis of the cause of renewal of any parts of which any appreciable quantity have to be renewed annually. The mere fact that a machine is constantly employed on the manufacture of a certain part should immediately direct the Works Manager's staff to an investigation into the cause of the demand.

(f) By the elimination of the more expensive metals wherever possible.

(g) By the judicious use of welding and patching, it being remembered that all patching likely to prove a source of maintenance at sheds should be rigorously avoided. This point may be illustrated by a short account of the work done at Horwich in the patching of cylinders since 1910 . Prior to that date little patching of cracked cylinders had been carried out. A policy of patching all cracks and fitting false valve faces to practically all cylinders whose barrels were in such condition as to be likely to run for another ten years was initiated in 1910. Since that date 197 cylinders have had barrel patches or pegs fitted, and 85 cylinders false faces at an expenditure of the time of two fitters. The resultant economy has been a cylinder moulder and his mates, the machining of 256 new cylinders, and the cost of removing and replacing the patched and faced cylinders. 


\section{LANCASHIRE \& YORKSHIRE RAILWAY.} MASTER OPERATION CARD.

$$
\text { MACHINE SHOP }
$$

$$
\text { Pisten Talue thead }
$$

Drawing No 12380 article. Pesten Walue thear

Pattern No 1255

\begin{tabular}{|c|c|c|c|c|c|c|c|c|c|}
\hline $\begin{array}{ll}\text { Opera- } \\
\text { tion No. }\end{array}$ & Description of operation. & & 甬的. & \begin{tabular}{|l} 
Fix- Maching \\
tures. No \\
\end{tabular} & $\begin{array}{l}\text { Sec. } \\
\text { tion. }\end{array}$ & & d. & H. & $M$ \\
\hline $1^{s t}$ & Tuming r Borem & 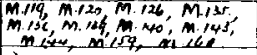 & & 231 & 9 & 3 & 6 & 2 & 30 \\
\hline $2^{n a}$ & 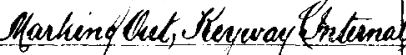 & & & Bemeh & 8 & $\therefore$ & 9 & & 34. \\
\hline $3^{\frac{r d}{w}}$ & Slottine. Meyeray & M. 391 & & 183 & 2 & & $42^{4}$ & & 14 \\
\hline $4^{2 x}$ & Haching Out. Howway fiocternal & & & Bench & 8 & & 9 & & 34 \\
\hline $5^{8}$ & dlot Edulling Mequay & M 390 & M: & 11 & $y$ & & 42 & & 17 \\
\hline $6^{9}$ & SFilting ue gor Drillenep. & & & Bench & 8 & & & & \\
\hline$\gamma^{\circ 6}$ & Qulling rofupung & $M .130, M .113, M .129$ & $\mid \begin{array}{l}M 2 \\
m \cdot 3\end{array}$ & 33 & $\boldsymbol{y}$ & $y$ & $8 \frac{1}{2}$ & 6 & 0 \\
\hline $8^{26}$ & 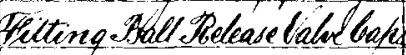 & & & Bench & 8 & & & & \\
\hline $9^{9 x}$ & Facengat $=d o$ & & & 240 & 9 & & $\gamma^{2}$ & & $2 y$ \\
\hline $10^{2}$ & Wetting :ollt Thelease balues 1 & & & & & & & & \\
\hline & Seating a bunding mbotes I & & & Bench & 8 & 5 & $94^{\frac{3}{4}}$ & 4 & $y$ \\
\hline $11^{\circ}$ & Adicuterno Penos & & & 240 & 9 & 3 & $0_{2}^{1}$ & 2 & 11 \\
\hline & & & & Total. & & 22 & & 16 & $5 Y$ \\
\hline
\end{tabular}

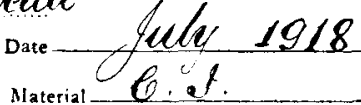

FiG. 4. 
Only 9.22 per cent. of the cylinders dealt with have been eventually scrapped and the Outdoor Locomotive Department have generally been unaware of the fact that the engine had repaired and not new cylinders.

(h) Is so per cent. of the engines stopped for works repairs are taken out of service on account of the condition of the boiler, a close watch on the trend of boiler repairs is necessary and a statistical record is kept as shown in $\dot{F}$ ig. 6 .

The efticiency of the methods of boiler repairs in the Works is checked by the reports of three Boiler Inspectors on the Works Manager's staff, specially selected for independence and matureness of judgment in connection with hoiler work. These Inspectors report quarterly on the concition of the boilers examined. A summary of the reports. for the last nine years is also given in Fig. 6, from which it will be seen that, in spite of the lact that the ratio of the total number of boilers repaired to the total engines in stock is becoming smaller, the condition of the boilers generally shows a steady improvement.

The Erecting Shop usually represents about 25 per cent. of the total area of a locomotive repair shop; every effort therefore should be directed to reducing the time spent on the erecting shop pits to a minimum.

It is good policy to have a small stock of boilers of each class tubed, mounted, and tested ready to drop into the frames as soon as the frame repairs permit after the old boiler has been lifted out.

To avoid transport of boilers, as much of the boiler repairs as possible should be carried out in the erecting shop. By this is meant such repairs as do not involve machining other than that which can be done by pneumatic or electric portable tools of which there should be a generous supply; all such tools should be under the special supervision of one man and such an occurrence as an inefficient tool, an air leakage or waiting for a tool should be made an impossibility. The Author in his own practice has to a large extent standardised patches which are sent across from the boiler shop shaped and drilled. In this connection it should be noted that no hardening up or renewing of stays or rivets should be carried out except after examination or on the written instructions of a foreman boilermaker specially allocated to this duty, otherwise much unnecessary work will be done. 


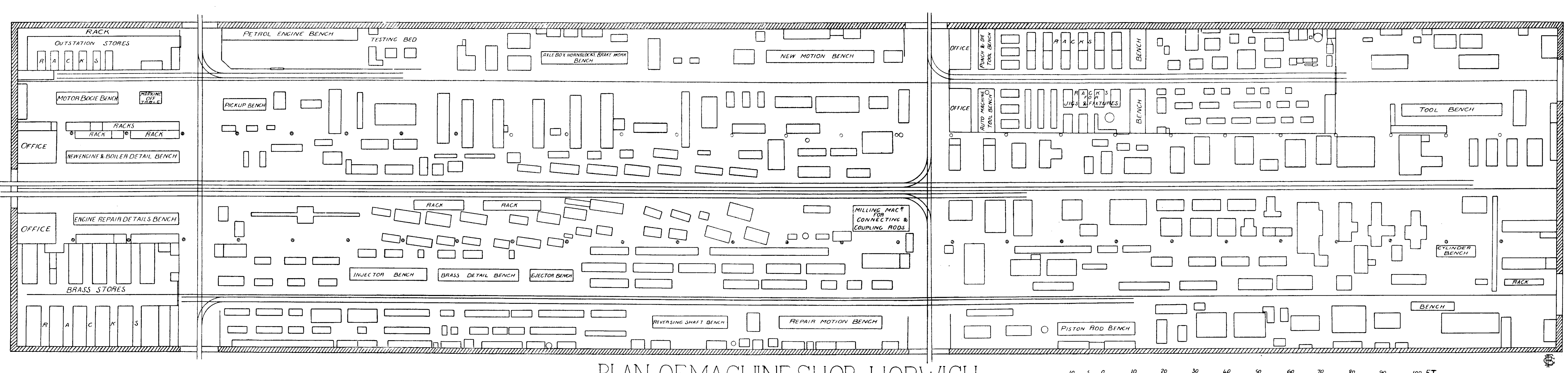


WORKS MANAGER'S OFFICE, HORWICH.

\section{CHIEF MECHANICAL ENGINEER'S DEPARTMENT. \\ 26 th April, r920.}

Summary of Boller Inspeotors' Report, 1911 to 1919 Inclusive.

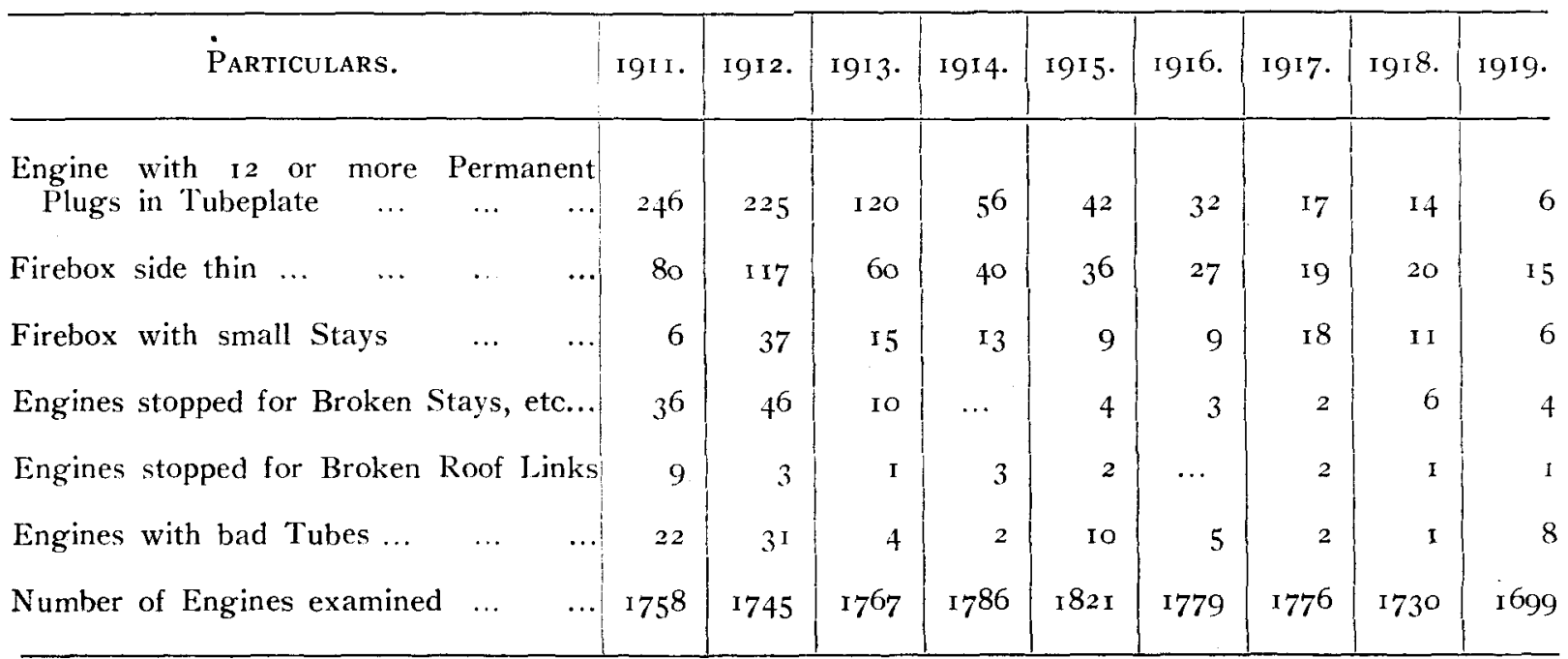

FIG. 6 . 


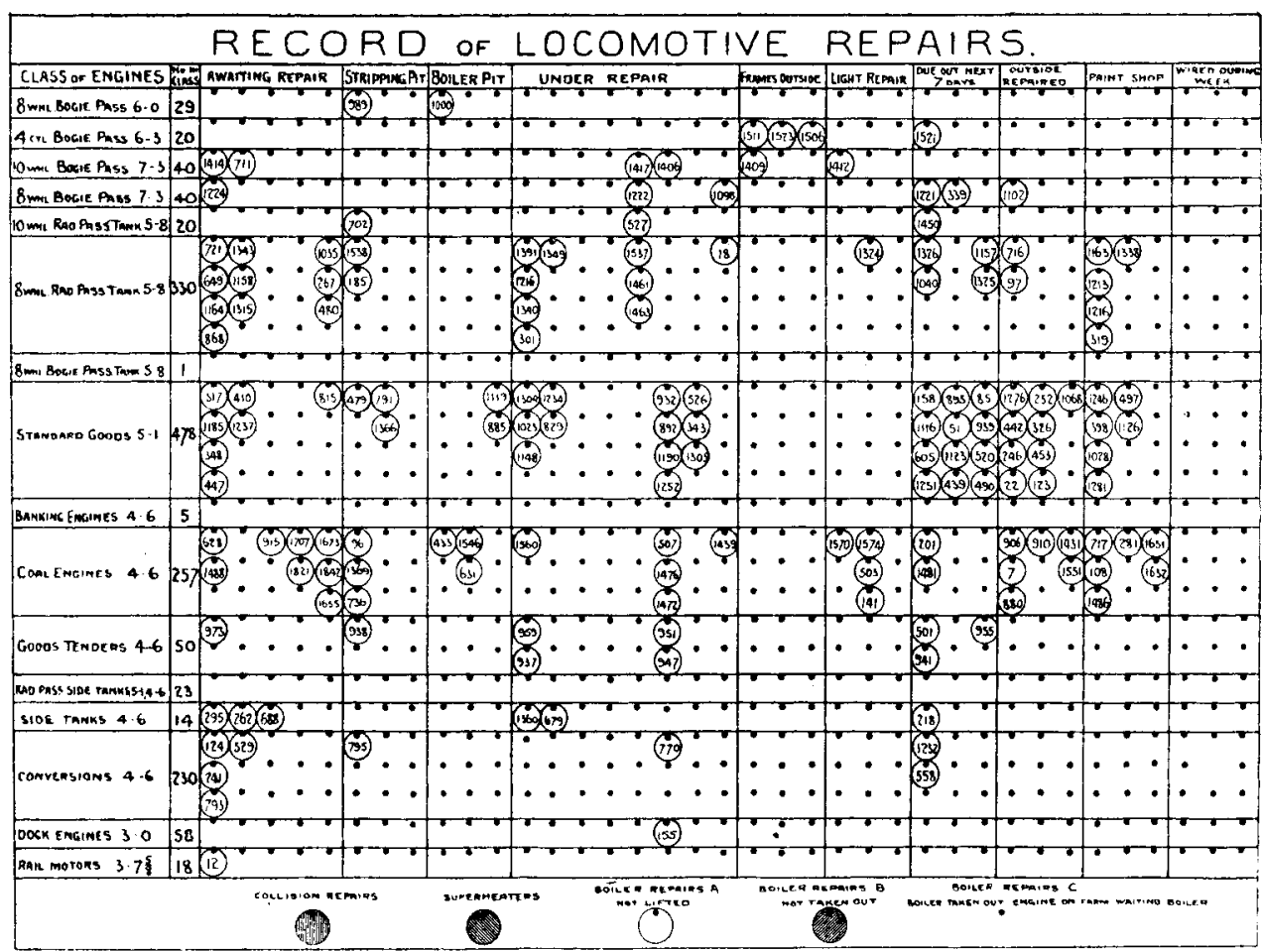

FIG. 7. 
While systematic scheduling of dates on which repair material is to be ready and engines are to be ready for trial is essential, such scheduling is ineffective unless regulated and modified by a daily foremen's conference consisting of the machine, erecting and boiler shops, foundry and smithy foremen as official members, with other foremen called in as required. At Horwich this conference is presided over by the Chief Works Inspector. Supplementing this daily foremen's conference is the work of the progress man attached to each of the principal shops. The progress man's sole duty is to follow up the material required by the chargehands according to the output boards for repaired engines, and the schedule for new engines. An illustration of the repaired engine output board is shown in Fig. 7 .

The Author would like to emphasise the importance of statistical information as the only possible method of keeping in close touch with the general progress in a large works, but at the same time, the greatest care has to be exercised that system and statistics do not run riot, creating a large number of inspectors and clerks producing information which cannot be digested and serves no useful purpose.

In dealing with engine repairs the work continually fluctuates, due to defects developing on examination after stripping and to changes in the requirements of the outdoor department; daily changes are therefore necessary in the repair programme, and the method of conference by the foreman enables immediate decision to be taken to meet the change of circumstance.

Before proceeding to describe the method adopted at Horwich in regard to the organisation for dealing with locomotive repairs, the Author would like to emphasise a few cardinal points which have, so far as possible, been always kept prominently before the Management at Horwich :-

(I) The necessity for keeping the boiler stock young; the $L$. and $Y$. have a definite renewal fund which permits of the building of boilers at a rate equivalent to a life of 16 to 17 years.

(2) The desirability of reducing firebox patching to an absolute minimum, vide the table in Fig. 6 .

(3) The importance of the greatest possible use of machinery in order to economise labour.

(4) The adoption of piecework or payment by results throughout the Works coupled with an endearour to secure the reasonable and intelligent co-operation of labour in obtaining a maximum output. 
(5) The infusion of a spirit of broadminded economy and esprit-de-corps into the supervisory staff.

(6) The most vigorous adhesion to standards; in this connection the Author regards the Drawing Office Staff acting in collusion with the Outdoor Locomotive Depart. ment as tending unconsciously to be the worst offenders against standardisation; it is generally far too easy to set a radical change in motion in some small detail which may have far-reaching consequences.

No alteration should be permissible in any drawing which has not been considered by a Committee representing the Works, Drawing and Outdoor Locomotive Departments

Adherence to old standards which are unsuitable in strength or design for the mere sake of standardisation is, of course, undesirable.

The organisation of a works for carrying out the above principle consists of five distinct groups :-

(I) The Management, whose functions are to direct general policy, regulate and balance the general flow of work, initiate the larger measures of economy and reform, the broader negotiations with labour, and the education in the shops of the apprentices.

(2) The Inspectorate, whose functions are to eliminate defective material or appliances, to direct the Management's attention to waste of material or labour, and to regulate the flow of work in detail.

(3) The Foremen, whose functions are to carry out the policies initiated by the Management and Inspectorate, to apply their specialist knowledge to improvements in manufacture, to direct the Management's and Inspectorate's attention to directions in which economy can be effected, directions of which they alone can have knowledge owing to their daily intimate contact with the work, to regulate the flow of work within their shops, and to conduct the direct negotiations with labour in regard to prices.

(4) The Clerical Staff, whose duty is to keep the very numerous records of all kinds required in a large works and to analyse the statistical records, and while omitting the record in writing of no really vital matter, to see that correspondence is reduced to the lowest possible limit. Many records and returns are often kept that are unnecessary or no longer serve any useful purpose, because somebody in years past started such records or operations, and it has been nobody's business to stop them. 

above.

The Author does not propose to give examples of the

So far no mention has been made of two groups in the organisation, which do not come under the works management directly, but whose work is of the greatest importance in the whole unit; these are the Accounts Office and the Testing Department. In regard to the former it must be remembered that there is no essential need for the Management to know the actual cost of every article manufactured or repaired; no works, except those engaged in selling a definite standardised article, have this knowledge, as is evidenced by the fact that no firm will give a firm quotation on a repair job except where they have had a long experience in a particular type of repair work.

It is essential, however, to have accurate costings of groups, i.e., the cost of repairs each year of each class must be known, as must also the cost of each batch of new engines; these costs again should be subdivided into the costs of boilers, smokeboxes, tanks, frames and stays, cylinders, valves, motion, wheels and axles, brake gear, injectors, piping, etc. This method of costing may be carried out by some companies; it should be obligatory on all; but it must not be carried too far into detail as otherwise it will be impossible to digest the information supplied, so a very slight expansion of the headings indicated is sufficient. At the same time, the Works Manager should be able to call for and obtain within a reasonable time the cost of any article; this is the case on the L. and Y. Rly., though the method of subdividing the cost of class repairs into cross headings of groups has not as yet been adopted.

It may not be obvious why extensive costing is not of great value in locomotive repair work, but a little consideration will show that the price of materials is dictated by the outside market, and the piecework prices of labour are fixed, and all reductions of cost must be made by new methods or new machinery or economy in material. Whether these reductions are being made is revealed by the balance sheets and ledger accounts for new machines, by the wages sheets of individual shops, and by the returns of scrap sold or utilised.

The broad costing divisions show tendencies; they indicate, for instance, in the case of tanks, whether the time is coming when a large number of new tanks would not be a more profitable investment than repairing the old ones. These broad costings must be supplemented and read intelligently concurrently with statistical information. 
In addition to the above costing and statistical checks on the efficiency of the organisation, the Management must have other figures constantly before them; on the $L$. and $Y$. this consists of-

(I) Monthly statements of the weight and cost of materials issued.

(2) Weekly statements of the wages paid; and number of men employed in each shop.

(3) A cross division of the wages paid under the following heads :-

Engine repairs.

Boiler renewals.

New engines.

Renewal of machinery and plant, subdivided under :-

(a) Machinery and fout generally.

(b) Engines and boilers.

(c) Hearths and furnaces.

(d) Cranes.

(e) Sundries.

Other workshop expenses, subdivided under :-

(a) Foremen.

(b) Checking and Inspectors.

(c) Cranemen, Tramwaymen, Sty. Enginemen, etc.

(d) Labourers:

(e) Light and Power.

$(f)$ Tools and Fittings.

(g) Pattern-making.

(h) Sundries.

Repairs to Premises.

Y. Orders.

Western and Central Electrified Lines.

Stores and other credits.

G.C. and other items.

In addition to this, in many cases Works Orders are issued to serial numbers for special work, such as repairs to a number of cranes, installation of new plant or machines, special repair jobs, etc.

The Author is of the opinion that in general it is probable that the staff employed on cost accounting and statistical work is insufficient in railway shops, but any advance in the direction of an increase requires to be made with the greatest deliberation and caution, and the value of each step requires to be proved on a financial basis; much, however, can be 
done by a simple system of card indexing and card recording to provide the necessary statistics and information from the routine shop records with an absolute minimum of clerical labour.

The cost of castings, forgings, and smithy work is watched by means of balance sheets which are prepared on the same lines as if the smithy, foundry or forge were working as an outside shop supplying the machine, erecting and other shops; therefore so far as the supply of semi-manufactured material is concerned, the Works Manager is in the position of knowing exactly how he stands in regard to the comparative costs as compared with supplies from outside manufacturers. Owing to the standardisation of the product the actual works cost is necessarily little, if any higher than that of a manufacturer, while the manufacturer's general charges, which are bound to be high on account of his necessity for advertising, preparing quotations and estimates, etc., are saved.

There is a further test of efficiency and financial solvency. The Outdoor Locomotive Department must be considered as the customers of the works. No commercial works can be solvent that has dissatisfied customers. Unfortunately there is and can be no financial test of the commercial solvency of a locomotive repair.works, but the satisfaction or otherwise of their customers, the Outdoor Locomotive Department, is probably the best possible test under the circumstances. The policy of the works should therefore be to invite complaints from the Outdoor Locomotive Department, and this is done as far as possible on the $L$. and $Y$. Railway by the system of returned waybills, which is described in Appendix $A$, and by the trial run of each repaired engine on an easy traffic job, the report of the trial being made by a driver who is independent of the works staff, and is not hampered or prejuciiced by the presence on the engine of any of the men who repaired it.

This view of a function of the Outdoor Locomotive Department must not be taken as committing the Author to support of the view that the Outdoor Locomotive Department should be under any control other than that of the Chief Mechanical Engineer. Any such system means the setting up of co-equal rival authorities in a technical subject within one organisation which cannot make for harmony or efficiency.

The second group, the Test Room, should be entirely independent of the Works and subordinate only to the Chief Mechanical Engineer; its function is to criticise the works 
product, to supply the works with the best of material, and to supply the works with the solution of any mystery that may be submitted to it.

The nearest possible approach to the best results in dealing with locomotive repairs is only attainable if the whole of the grades and groups engaged in the work deal with it in a spirit of self-sacrifice, completely sinking their own personal interests for the good of the whole; the general outline of locomotive repair work is so standardised that except in so far as progress on the broad lines indicated earlier in this Paper is concerned, there is more engineering of human nature than of material in the work.

The Author gives two appendices to the Paper describing the routine of engine repairs and the application of limit gauges and progressive sizes in the machine shop, for which he is much indebted for the former to his Chief Works Inspector, Mr. Buchan, and for the latter to his Assistant Machine Shop Manager, Mr. Walkden. These two appendices will, to many members, be more interesting than the body of the Paper inasmuch as they describe actual facts rather than theories.

\section{APPENDIX A.}

\section{SYSTEM OF LOCOMOTIVE REPAIRS AT L. AND Y. LOCOMOTIVE WORKS, HORWICH. \\ (i) STOPPING OF ENGINES AT SHEDS FOR WORKS REPAIRS.}

Engines are stopped at sheds on the recommendation of either the Boiler Inspector or Locomotive District Superintendent, and the receipt of a waybill at the Works is a notification that repairs are required to such engine.

The waybill is filled in, in duplicate, by the Locomotive District Superintendent, and forwarded by him to the Works with a tubeplate diagram and a boiler stay chart.

The Inspection Department, when calling such engines into the Works, pay due regard, after conference with other departments concerned, to :-

(a) Particular type of engine most urgently required by Running Department, varying with the season.

(b) Ability or convenience of the Repair Shops to deal with such repairs as may be required.

Light repairs are generally dealt with at once. 


\section{(2) WAYBILLS.}

Upon receipt of the waybill at the Works the duplicate is sent to the Inspection Department.

The waybill is a four-page sheet; on the front outside is stated the number and class of engine, the shed to which it belongs, date stopped for repairs, experimental fittings (if any), flaws, date of last general repair, mileage since last repairs, mileage of tubes and crank axle, also additional remarks.

The first inside page provides a list of main items such as frames, hornblocks, wheels, axles, tyres, axleboxes, cylinders, valves and valve gear, etc., etc., for the engine, and for the tender, with space for remarks.

The second inside page includes faceplate fittings, boiler, and tender tanks and coal bunkers.

The back, or fourth page, provides space for Works remarks upon details of repairs effected whilst engine was in the Works, such as :-

(a) Date left Worlis.

(b) Whether boiler had been out of frame.

(c) Cylinders out of frames.

(d) Experimental fittings, also boiler pressure, registered number of boiler, thickness of firebox side, type of valve and thickness of valves.

The bottom portion of this page also provides a space in which the Shed Foreman can record the behaviour of the engine in traffic during the first six days after receipt from the Works.

When the latter space is filled in, the waybill is returned to the Works for the Works Manager's information and provides ground for exercising disciplinary methods in regard to the shops concerned.

\section{(3) CALLING IN TO THE WORKS.}

The number of engines called in weekly depends upon the weekly output of repaired engines.

The number of engines of any one type standing at sheds awaiting repairs is not allowed to exceed to per cent. of that particular class.

A forecast of the engines likely to be sent into traffic during the following week is made, based on the above premises, and an equal number of engines are called in from the Sheds. 
As far as possible, such engines are called in from particular sheds as will permit the drivers and firemen of the outward-going engine bringing back with them one of the engines called in for that week, a considerable item in wages thus being saved.

\section{(4) INSPECTION PRIOR TO REPAIR.}

Upon receipt of an engine at the Works for repairs an inspection is made whilst the engine is still in steam, if possible.

This examination includes trial of injectors, whistle, steam sand and cylinder mudcock gear, cylinders and valves, ejector and boiler mountings in general, also tenders and tanks for leakage, etc.; any items missing are noted, and the brake cylinders and pipes are tested.

Where any of the items are found to be in good order the Inspector marks the waybill to that effect.

At the end of the inspection the fire is dropped, tenders and bunkers are emptied of coal (this being transferred to engines coming out of the shops), and the engine is placed in a loop to await a racancy on the stripping pit.

\section{(5) STRIPPING PITS.} follows.

The method of dealing with engines on these pits is as

Whilst fitters are uncoupling the motion and wheels, labourers are emptying the smokebox, taking firebars out, brick arch down, and sweeping the firebox sides so that as soon as the ashpan is dropped the boiler examiner may examine the firebox.

During the stripping the chargehand stripper thoroughly inspects all parts and decides all bolt renewals needed in cylinders, horns, etc., spring brackets to be cut off for bushing, and his report is added to the waybill sent to the Erecting pits.

Heavy repairs (which alone are dealt with on the Stripping pits) are, in accordance with the Boiler Inspector's. report, subdivided into the following classes.

Class A.-Engines which have no large structural defects with the boiler and frebox in such condition that they can be repaired in the frames. All repair work for this class of repair should be dealt with as expeditiously as possible as it will be required back again to the engine in 18 days. 
Class B. - Cases where the boiler has to be lifted and can be repaired in Erecting Shop upon the Boiler pit or can be supplied with a spare boiler.

This also applies to cylinders.

The work for this class of repair has to be returned to the engine within 21 days.

Class C.-All cases of heavy structural repairs such as cylinders, footblock, etc., or boilers needing Boiler Shop repairs. These engines are put outside the shop when stripped until the main details are sufficiently advanced towards completion as to justify the engine being placed upon the Erectors' pit, but no spare boiler immediately available.

Repairs of general details to such engines are not proceeded with in the other shops until notice is given, which must be at least three weeks before engine is booked out.

Class $\lambda$ boiler repair in frames. Work for this class of repair is expected back in the Erecting Shop within 18 days of stripping.

The Chargehand Stripper's report having been received in the Office on the sixth day with the order cards which have been made out showing all requirements in the way of new or repaired articles, and also the report from special examiners as to condition of motion, valves and faces, cylinders for renewal or boring, axleboxes, frames, etc., the actual ordering of the material upon the shop concerned is proceeded with.

These printed order cards are made out to the following benches, viz., Piston bench, Engine-repair Detail bench, Motion bench, Brasswork bench, Cylinder bench, Pick-up and Spring bench. Copies are then made on tear-off pads, in triplicate, one set of which, with a copy of the Shed waybill, is sent to the Erector upon whose pit the engine is to be repaired; the second set is sent to the Material Progressman (a description of whose duties is given later), whilst the third set is sent to the. Department concerned with the repair or supply of the detail required.

The original order cards are forwarded to the Finished Work Stores in the Erecting Shop; there each detail which can be supplied from the stock in hand is marked off.

The cards are then forwarded to the holders of the third copy, and the Finished Work Storekeepers' mark indicates to all concerned that such details will not be paid for. 
Upon receipt of these cards shop orders are issued to the various chargehands in the Repair Department, and as the work is completed the Chargehand enters opposite the article the date of supply; no work can be paid for other than this.

The cards are made to serve as a very useful check upon arrears in the details of any particular engine; each Chargehand is provided with a box in which he keeps all his cards in three batches, each batch in numerical order; the front group represents material due out from his department in the next fortnight, the second group due out in three weeks, and the third due out in four weeks.

All detail work is expected out of the repair shops at least seven days before the engine is due out of the Erecting shops; should, from any cause, an item be still unsupplied on the seventh day prior to the output date of the engine, the card is taken out of the box and hung upon a special board provided, which is headed "Work not supplied for engines due out in seven days or less" ; the arrears are thus kept prominently before both the Progressman and the Foreman, and this has a tendency to keep arrears to a minimum.

In every department on the Works an Output Board, forecasting the output for the next four weeks, is posted, and this Board has the engine numbers re-arranged weekly as a result of conferences held in the Chief Inspector's Department with the Foremen concerned.

It is easy for the Chargehand, after each weekly alteration, to re-arrange his cards accordingly.

In the event of any unforeseen development during the erection of an engine, such as the breakage of castings, or items having been orerlooked on the Stripping pit, application must be made to the Material Progressman, who issues a supplementary order card.

This card is of a different coiour to the ordinary card and has a column in which must be stated the reason for such late order, thus checking any laxity of supervision, reckless handling of material, or carelessness in delivery of repaired details.

\section{(6) BOILER PIT.}

In the case of an $A$ class repair which has been placed on a special pit set aside for boiler repairs, all loose rivets in frames, platforms and splashers are renewed, and bunket 
sides and bottoms repaired; this work is expected to be completed in 12 days, when the engine is transferred to the Erectors' pit.

A $B$ class repair is dealt with in the same way, except that the boiler is in some cases lifted and repaired at the end of the Boiler pit whilst the frames, bunkers, etc., are receiving attention.

If the boiler needs such heary repairs as tubeplate renewals or $\frac{1}{2}$-side patches, then it is sent to the Boiler Shop and one of a similar type is pressed forward on the Boiler Mounting pit so that it may be tubed and tested in time for delivery to coincide with arrival of frames upon Erectors' pit.

Where possible, with engines needing $\mathrm{C}$ class repairs, the frames, etc., are repaired on the Boiler pit before being sent outside in order to prevent delay in dealing with the engine when the frames are brought back into the shop.

The following table shows the time allowed for the different classes of repairs :

\begin{tabular}{|c|c|c|c|c|}
\hline Pit. & $\begin{array}{l}\text { "A" Repair. } \\
\text { No of days } \\
\text { allowed. }\end{array}$ & $\begin{array}{l}\text { "B" Repair. } \\
\text { No. of day's } \\
\text { allowed" }\end{array}$ & $\begin{array}{l}\text { "C" Repair: } \\
\text { No. of day: } \\
\text { allowed. }\end{array}$ & \\
\hline Stripping $\quad \ldots$ & 6 & 6 & 6 & Note. "C" type \\
\hline Boiler & 12 & I4 & I 4 & $\begin{array}{l}\text { only brought } \\
\text { into shopsagain } \\
\text { when work for }\end{array}$ \\
\hline Erecting $\quad .$. & 12 & 14 & 18 & \\
\hline $\begin{array}{l}\text { Total days } \\
\text { in Shops }\end{array}$ & 30 & 34 & $3^{8}$ & \\
\hline
\end{tabular}

In connection with $A$ class repairs care is taken to record all steamtight stays on the stay chart.

In no case is the number of steamtight stays allowed to exceed $3^{\circ}$ in all nor must any group of such stays consist of more than ten in number.

Should additional stays (steamtight) be put in at the sheds, these must be correctly recorded upon the chart so that when the engine is again sent to the shops for repairs the Boiler Examiner on the Stripping pit can at once say whether or not the boiler must be lifted.

After lifting, all steamtight stays are rivetted over and a blank stay chart is issued to sheds, the cancelled one being filed. 
Similarly tubeplate diagrams are issued showing in the case of part set renewals, which tubes have been so dealt with, the class of tube put in, also holes either permanently plugged or bushed for swaged tubes owing to cracks in tubeplate holes.

This diagram is also kept up to date at sheds, and replacements, etc., are recorded thereon.

As a final summary of the system of Engine stripping, Examination and Order progression a card system is used.

These summary cards, described below, when completed, are returned to the Chief Inspector's Office, and a monthly return of the average time taken for the various processes is shown.

\section{ENGINE STRIPPING EXAMINATION AND ORDER PROGRESS CARD.}

Engine No.

Class of repair.

Chief Inspector or Principal Foreman to initial and certify when work was completed.

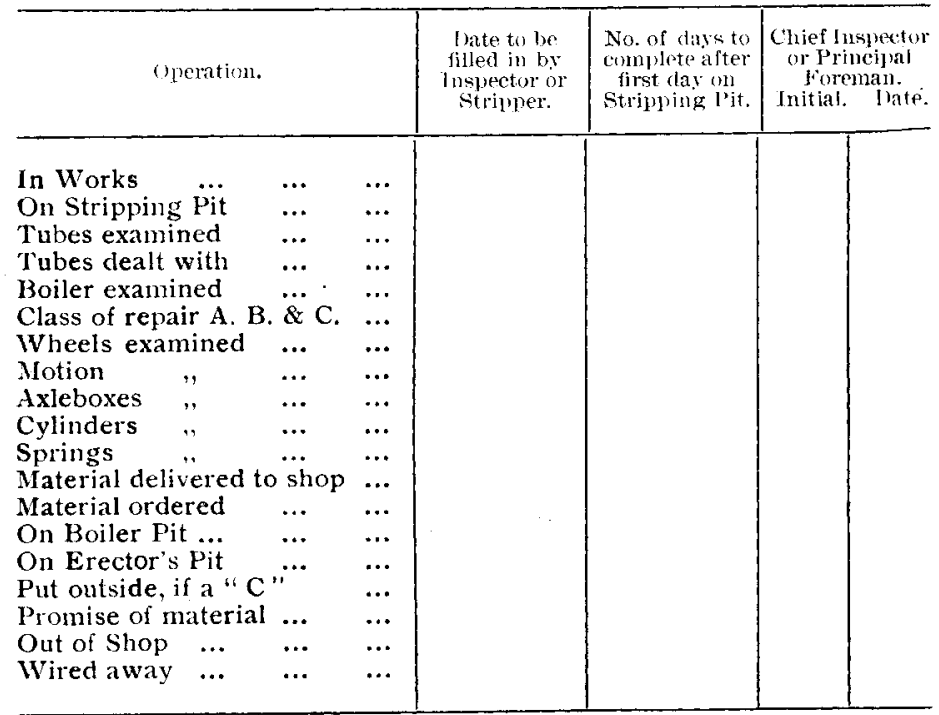

Iny card not completed within to working days of engine being on Stripping pit to be sent to Works Manager's Office for inspection. 
The cards will be issued by the Works Inspector, and when filled up, returned to his Office so that the information may be summarised.

In actual practice the summary for two separate months working came out as follows :-

\begin{tabular}{|c|c|c|c|}
\hline es sent away which ha & & April. & $\begin{array}{c}\text { May. } \\
66\end{array}$ \\
\hline Average days on Stripping pit & & $\begin{array}{r}59 \\
6.19\end{array}$ & 6.46 \\
\hline Average days on Boiler pit & & 7.85 & 6.65 \\
\hline Average days on Erector's pit. & $\ldots$ & 27.96 & 26.06 \\
\hline Total time in Shop & ( & 38.98 & 37.57 \\
\hline led off outside & $\ldots$ & 7.33 & 6.95 \\
\hline Average days, tubes examined & $\cdots$ & $3 \cdot 33$ & 3.92 \\
\hline Average days, tubes finis & $\cdots$ & $7.7 \mathrm{I}$ & 8.9 \\
\hline Average days, boiler examined & & 2.87 & 3.01 \\
\hline Average days, wheels examined & $\cdots$ & 4.89 & 5.00 \\
\hline verage days, motion examined & $\cdots$ & 3.97 & $4 \cdot 5^{2}$ \\
\hline mined & $\ldots$ & 6.09 & 8. 12 \\
\hline cylinders examined & & 5. & 6.26 \\
\hline & & $7 \cdot 5$ & 7.83 \\
\hline ed from Eres & & 7.43 & 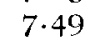 \\
\hline
\end{tabular}

\section{(7) DUTIES OF ERECTING SHOP PROGRESSMAN AND PROGRESSING OF MATERIAL.}

The delivery of material requiring repairs to the other shops is under the supervision of an Erecting Shop Progressman; he is responsible for seeing that all engine details are stewed or cleaned and delivered to the other shops within Io days from the receipt of the engine upon the Stripping pit.

$\mathrm{He}$ is also responsible for the delivery of all repaired details to the Erectors' pit to schedule, having regard to the position of the engine on the Output Board.

By a daily perusal of the Output Board and the duplicated set of ordered material lists (mentioned in paragraph 6) he is able to keep his finger on the pulse of the Erecting Shop requirements, and to anticipate them as much as possible so as to keep items from figuring upon the arrears list (issued daily).

The arrears list, which is compiled by the Progressman, contains all items not supplied to engines due out in the next 7 days, and a copy is placed before each Foreman at the daily conference, and later in the day is put before the Manager together with the remarks made at the conference by the Foremen concerned. 
Twice daily, at specified hours, the Progressman is interriewed by Chargehands who want such items as frame stays, hornblocks, etc., at an earlier date than the ordinary details; also by others who have material verging upon the arrears. date and not yet to hand.

\section{(8) FINISHED WORK STORES.}

In connection with the locomotive repair organisation is a Finished II ork Store combined with a Central Order Department.

The function of this store is to provide a daily and yearly record of new and repaired articles supplied to the Erecting Shop and the Outdoor Locomotive Superintendent; at the same time it ensures that a maximum stock is not exceeded or a minimum stock depleted; at any time the stock of any item may be ascertained by the card index system in the store. By this means a system of central ordering is possible, which in its turn permits of articles being ordered in considerable quantities with consequent economy in production. It also provides a perfect and complete check on payment for machining, and ensures a ready supply for the Erectors or Outdoor Locomotive Department of each article required.

\section{(9) ERECTING PITS.}

Generally speaking, four engines form an Erectors' pit; the usual complement of hands consists of (I) a chargehand, (2) five journcyman fitters, (3) three apprentices, (4) one hand driller, who acts also as labourer when not occupied with drilling, an additional labourer divides his time between two pits, sharing in any two-handed job as required, such as pinching or racking engine when valve-setting, replacing firebars, etc.

Upon receipt of an engine, or frames from the Boiler pit, the labourers at once scrape and clean the frames and hornblocks; the work of renewing loose horns and cylinder bolts is then commenced; where necessary the holes are opened out by drillers with portable electrically driven drills; fractured frames are chipped out to a feather edge and are afterwards oxy-acetylene or electrically welded, all studs upon cylinders and boiler (in the case of an $A$ repair) are sounded and doubtful ones renewed, broken ones being drilled out.

Inequalities are removed from hornblock cheeks, and the axleboxes (which, along with the brakework, etc., have 
been to the stewpot and are now delivered to the pit by the Stripping pit gang) are tried up in the horns, adjusted and marked off for boring.

If a B class repair the boiler will now be to hand, and 's at once placed in frames and fastened down.

Whilst the clothing belts are being fitted by a floating gang, the Erectors are, in the case of a changed boiler, setting the handrail brackets, jointing the steam tee pipe and steam pipes, fitting ashpan and firebar brackets.

When this work is completed another floating gang of labourers place the asbestos mattressing in position and the clothing gang are enabled to fit the sheathing in position, the cab is temporarily bolted, as is the smokebox, and the rivetters take these in hand.

Meanwhile the slide bars are set and motion with reversing gear fitted by one fitter and apprentice, whilst another pair will have taken the wheels in hand and be mounting the axleboxes, hanging springs, etc., in readiness for wheeling; a fitter will also be engaged during the operations in placing all pipes, on footplate and below, in position.

After wheeling, the engine is placed upon a cradle and the valves are set by micrometer in accordance to figures supplied from the Inspection Department.

These figures are issued on duplicate slips and based on Vernier measurements taken of ports and valves.

\section{(ro) RUNNING TRIAL.}

This takes the form of about four hours' working of branch passenger traffic.

Before trial the brake is tested by the Brake Inspector, who is responsible for the vacuum brakes and examination of all accessories.

The Inspector keeps and maintains records of the life of all diaphragms and brake parts, and reports monthly upon their life.

It is possible to run four engines per day in this manner, but an average of about three per day is maintained, not including Saturdays. Saddle tank and dock engines, along with steam rail motors, however, are run on trial in the Works yard and do not require to go on the Branch.

In all cases, at the conclusion of the run, the driver makes a report on the behaviour of the engines. Triplicate copies are then issued-one to the Trial Inspector, 
one to the Foreman of the Erecting Department, and the third is sent to the Chargehand, under whose supervision the engine was repaired.

As soon as the engine is ready to go out, it is carefully examined by the Trial Inspector for possible defects or omitted repairs. The Trial Inspector takes the engine for a short run in the Works yard, after which, should everything be found correct, the engine is wired into traffic, unless it requires painting.

The engine then goes to the weigh-bridge to have the weights adjusted, and during this adjustment the trial driver's report enables the Chargehand to rectify any minor defects that may have revealed themselves on trial. The Outdoor Locomotive Department are informed that the engine is ready for traffic unless it requires re-painting.

\section{(I I) PAINT SHOP.}

Engines are usually a month in the Paint Shop as at the old paint upon splashers, cab and sides, tanks and bunkers, needs removing with detergent before re-painting.

The clothing will, in the majority of cases, have been sent to the stewpans whilst the engine was on Boiler or Erecting pits and therefore is not in need of any further preparation.

\section{(i 2) RETURN INTO TRAFFIC.}

As soon as a repaired engine is wired into traffic the waybill is forwarded through the Outdoor Locomotive Department to the District Locomotive Superintendent of the district to which it is allocated.

The waybill at this stage has upon it the whole of the repairs stated in detail, the condition of firebox sides, thickness of valves, etc., etc., as previously mentioned in paragraph No. 2, and is accompanied by up-to-date stay and tube charts.

After the engine has been in traffic for six days the District Locomotive Superintendent fills in on the waybill repairs or adjustments which have been necessary during that period. The waybill is then returned to the Works and the defects are brought to the notice of the foremen concerned for explanation. 


\section{APPENDIX B.}

METHOD OF THE APPLICATION OF LIMIT GAUGES AND PROGRESSIVE SIZES IN THE MACHINE SHOP OF THE L. \& Y. LOCOMOTIVE WORKS, HORWICH.

The adoption of graduated sizes of pins and holes and the bushing of holes subject to wear are two valuable methods of effecting economies.

The parts to be handled in machine shop usually associated with "General Repairs" are-

Motion.

Valves.

Footplate Details.

\section{MOTION.}

The Motion is dismantled in lirecting Shop, examined, and results of examination posted on to Machine Shop, giving particulars of new parts required, which are replaced from a stock which is maintained and based upon past experience. manner.

The parts requiring repair are dealt with in the following

\section{MOTION PINS (Limit Gauge).}

The limit gauge system on motion is on the pin basis (owing to push and running fits being on one pin of one diameter).

Tolerance on motion pins is 0.0005 in.

The high diameter being the nominal diameter.

The low diameter being the nominal diameter minus tolerance.

The Motion Pins are manufactured in nine different sizes, the first five varying $0.005 \mathrm{in}$. each and the remaining four vary o.oroin. each, and each size is identified by a letter as follows :-

\begin{tabular}{ll|c|c|c|c|c|c|c|c|c}
\hline & J. & K. & L. & M. & N. & P. & Q. & R. & S. \\
Ifigh & $\ldots$ & $2^{\prime \prime}$ & 2.005 & 2.01 & 2.015 & 2.02 & 2.03 & 2.040 & 2.05 & 2.06 \\
Low & $\ldots$ & 1.9995 & 2.0045 & 2.0095 & 2.0145 & 2.0195 & 2.0295 & 2.0395 & 2.0495 & 2.0595 \\
\hline
\end{tabular}

The pins are turned on automatics with an allowance of o.oroin. to o.or $5^{\mathrm{in}}$. for grinding after case hardening. 


\section{HOLLOW MOTION PINS.}

When these pins are worn below minimum size they are annealed and expanded by means of a press and mandrills; these mandrills run in sizes from No. i to No. 9, each varying in diameter 0.005 in. They are then re-hardened and ground to size required.

A substantial economy has been effected by this means.

\section{HOLES.}

All rods are bushed with case-hardened bushes in rapidly wearing holes, and when worn the bush is pressed out and the new one inserted and ground to diameter required, which is governed by the size of hole in which the pin is fixed.

\section{LIMITS.}

The minimum variation allowed between pin and hole is that demanded for running fits, i.e., $0.0025^{\mathrm{in} .}$

The maximum variation is 0.005 , thus giving a manufacturing tolerance of 0.0025 .

\section{CHART SIZES OF RUNNING AND PUSH FITS. RUNNING FITS.}

\begin{tabular}{lc|c|c|c|c|c|c|c|c|c}
\hline & J. & K. & L. & M. & N & P. & Q. & R. & S. \\
High & $\ldots$ & 2.0045 & 2.0095 & 2.0145 & 2.0195 & 2.0245 & 2.0345 & 2.0445 & 2.0545 & 2.0615 \\
Low & $\ldots$ & 2.0025 & 2.0075 & 2.0125 & 2.0175 & 2.0225 & 2.0325 & 2.0125 & 2.0525 & 2.0625 \\
\hline
\end{tabular}

\section{PUSH FITS.}

\begin{tabular}{ll|c|c|c|c|c|c|c|c|c}
\hline & J. & K. & L. & M. & N. & P. & Q. & R. & S. \\
High & $\ldots$ & 2.0005 & 2.0055 & 2.0105 & 2.0155 & 2.0205 & 20305 & 2.0105 & 2.0505 & 2.0605 \\
Low & $\ldots$ & 2 & 2.005 & 2.010 & 2.015 & 2.020 & 2.030 & 2.040 & 2.050 & 2.060 \\
\hline
\end{tabular}

\section{REVERSING SHAFT.}

The journals of the reversing shafts wear slightly, and when worn oval to the extent of o.oroin. they are turned up in lathe to graduated sizes, each varying o.oI 5 in., and when worn to the minimum diameter a sleeve bush is shrunk on and returned to standard size. Standard sizes of journal

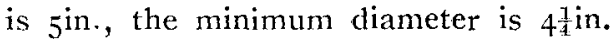




\section{REVERSING SHAFT CARRIER BRACKET.}

The bracket is bored out to allow for the fitting in of a cast iron sleeve bush; this diameter remains constant. The internal diameter of these bushes is machined to graduated sizes to suit the shaft journals.

When these bushes are worn, they are re-bored to the nearest graduated size.

They are also interchangeable.

\section{RADIUS LINKS.}

These links wear mostly in the centre owing to the notching up when running; this necessitates them being ground parallel, and radius blocks fitted to suit.

\section{RADIUS BLOCKS.}

Radius blocks are machined to four sizes, varying

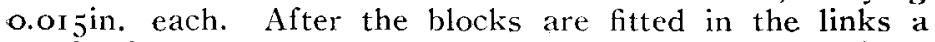
special fixture is used to mark the blocks whilst in position in the shaft, which ensures the holes being in line with the centre of the shaft.

\section{REVERSING SCREWS.}

The reversing screws are made in two sizes, standard zin. diameter, and $\frac{1}{18}$ in. above. When these are worn thin on the thread they are scrapped.

\section{REVERSING SCREW NUTS.}

These are also made in two sides, standard and $\frac{1}{16} \mathrm{in}$. above. The reason for this is, when the standard nut has worn thin on the thread they are machined out a $\frac{1}{1}$ in. larger in diameter, thus giving the nut another life.

\section{PISTON RODS.}

Piston rods wear smalier in diameter at the middle than the ends, due to the friction of the packing.

This necessitates them being ground to bring the rod parallel the whole of its length.

They are ground in five graduated sizes, each varying o.ozIzin., standard size being 3 in. diameter, minimum diameter $2 \frac{5}{8}$ in.

After the grinding operation the rod is then dealt with on the bench to have the crosshead and cotter fitted.

Occasionally the crosshead has expanded leaving no 
cotter draw; in that case a crosshead is taken from stock and fitted, leaving a lin. draw.

The old crosshead is placed in stock, and when new rods are being turned these crossheads are despatched to the lathe and the rods turned on cone to suit, thus getting the crosshead into service again.

\section{CROSSHEAD GUDGEON PINS (EFFECT).}

Gudgeon pins are examined, and if worn more than 0.0312 on the little end or slide block bearing, they are renewed. These are made in two sizes on the slide block bearing standard, and $\frac{1}{16}$ th above to give slide block another life.

They are manufactured on the automatics, case hardened and ground.

\section{PISTON HEAD.}

The piston head, if found to have a clearance in cylinder bore of $\frac{3}{16} \mathrm{in}$., is condemned for that particular engine. Should the diameter of the head be over standard size, it is placed in stock and machined to suit cylinder nearest to its diameter. The bore and cone portion for piston rod bearing remains constant in all cases and is therefore interchangeable.

Clearance allowed between cylinder bore and piston head for new or re-bored cylinder is o.or gin.

\section{SLIDE BLOCKS.}

Slide blocks wear very slightly in the gudgeon pin hole; in cases where the wear exceeds o.oloin. they are re-bored to a $\frac{1}{1}$ in. above standard size. This is sufficient to wear the block and flange to their minimum thickness.

\section{SLIDE VALVE SPINDLES.}

The flat valve type of spindle, when in for repairs, is generally found to have expanded at the buckle, and if this expansion exceeds o.orgin. above standard, it is sent to the smithy for closing, and there machined up to standard in the buckle. Should the spindle have worn below the minimum diameter a new end is welded on to the buckle and machined to the standard diameter.

The" standard diameter of the spindle is $2 \frac{1}{8}$ in. As the spindle wears more in the centre than at the end, due to the friction of the packing, this necessitates it being ground to bring the rod parallel the whole of its length. 
They are ground to nine graduated sizes, varying 0.015 in. from $2 \frac{1}{8} \mathrm{in}$. diameter to $2 \mathrm{in}$.

\section{VALVE SPINDLE CROSSHEAD.}

The same remarks apply to fitting of crosshead to spindle as in the piston rod.

\section{VALVE SPINDLE AND PISTON PACKING.}

Packings are manufactured in graduated sizes in conformity with piston rod sizes.

\section{FOOTPLATE DETAILS.}

The injectors are stripped of all cones and plugs; scale removed from body and cones.

Valve seatings and cones are re-faced and adjusted.

\section{STEAM VALVE AND TAPPIT VALVE SEATINGS.}

Due to the constant wear and repeated cuttings of the seatings, they rapidly become worn out. In order to increase the life of the body it is bored out and a bush fitted as a renewable seating.

\section{PIPE ENDS.}

Occasionally the thread on pipe ends becomes stripped; these are restored to standard by turning the ends down and sweating on a sleeve bush, afterwards re-cutting the thread.

After injectors are repaired they are tested for efficiency in lift and delivery.

\section{EJECTORS.}

The ejector is stripped of all plugs and cones, thoroughly cleaned and examined, and cones that have been cut due to action of the steam are re-turned and adjusted. In all wearing parts renewable seatings are fitted wherever possible.

The disc plate requires turning up and facing to the driver's application handle.

All glass gauge cocks, lubricator cocks, etc., are stripped, examined, and new plugs fitted where required. In cases of taper plugs they are ground only. Parallel plugs are ground and asbestos packed. 
The Chairman: Gentlemen, I think you will all agree that we have had a very interesting paper and that the thanks of this Institution are due to Colonel O'Brien for the paper and also for the very great trouble to which he must have been put in the collection and recording the facts contained in the paper. $\Lambda \mathrm{s}$ is usual at these meetings, before we open the discussion, I move that the very best thanks be given to Colonel O'brien for coming here to-night and reading his paper, which must have cost him so much time to prepare. As he points out, he has given us a paper which contains many opportunities for debate, and I hope that when the debate takes place on November 5th, all present here to-night along with others will attend and take part.

The object of the Institution is to give every member, to matter how little they have to say, a chance of taking part in the debates. In the other Socicties, such as the "Civil" and the "Mechanical," many people are apt to be overawed perhaps, or have not sufficient confidence to speak before such august assemblies. I am told that at the inception of our Society, the main idea was to give every member an opportunity of asking questions or airing their opinions without iear or favour and without regard to status. As Colonel O'Brien has said, an organisation cannot be carried on by one person, but only by everybody working together. In a large locomotive works, for instance, the management cannot carry everything on themselves. They must have people in those works whom they can trust, and I have found that if confidence is placed in a man, the best results are obtained from him. But you must have all men working with you. It is one of the essentials that every man should perform the work entrusted to him with the knowledge that he has the confidence of the man in charge. If the men who are here to-night will take to heart that they form part of the whole organisation, and that in addition to doing their bit, and doing it well, they likewise have the confidence of the men under their charge, I am sure that the feeling created will go far to get work carried through in a satisfactory and economical manner. It is no use putting a system, however good, into force unless you can get that system carried out properly.

With these few remarks I will ask someone to second the vote of thanks for the very interesting and able paper which Colonel O'Brien has presented here for the first time.

I think it is a compliment to this Centre for that gentleman to come here and read us his paper before it goes to London, where it will be given later. 
MANAGEMEN'T OF A LOCOMOTIVE REPAIR SHOP-O'BRIEN. 403

Mr. W. G. P. Maclure: I have very great pleasure in seconding the rote of thanks to Colonel O'Brien, but I had hoped someone other than a Great Central man would do so. I am sure that everybody is very grateful to Colonel O'Brien for his very excellent paper. I do not think that anything more is necessary at the moment; when we come to the discussion we shall be able to say more about it. 